\title{
Psychometric validity of the distress thermometer and problem check list in ART-naïv HIV infected patients in Northern Nigeria
}

\author{
Victor Olisah Obiajuluํ, Tajudeen Abiola ${ }^{2}$, Christopher Okpataku Izehinosen ${ }^{3}$, Reginald O Obiako ${ }^{4}$, \\ Ishaq Audu Aveka ${ }^{1}$, Bashir Yakasai Adam ${ }^{5}$, Taiwo Sheikh Lateef ${ }^{1}$
}

1. Department of Psychiatry, Ahmadu Bello University Zaria.

2. Medical Services Unit, Federal Neuropsychiatric Hospital Barnawa-Kaduna.

3. Department of Psychiatry, College of Health Sciences, Bingham University Jos.

4. Department of Medicine, Ahmadu Bello University Zaria.

5. Department of Internal Medicine, Kaduna State University, Kaduna State, Nigeria.

\begin{abstract}
Background: HIV diagnosis comes with a lot of worry and distress. Ability to objectively estimate this distress by non-psychiatrist will enhance early detection of psychological distress for intervention.

Objectives: To investigate the validity of the Distress Thermometer (DT) and its problem checklist in achieving early detection of mental distress among ART-naïve HIV infected patient.

Materials and Methods: A total of 90 ART-naïve HIV infected patients completed the DT and its problem check list, Hospital Anxiety Depression Scale (HADS), Oslo Social Support Scale and the 14-item Resilience Scale.

Results: The DT was positively correlated with all the measures of distress and reversely correlated with all the positive wellness in this study. The correlations were only significant for the negative measures of psychological wellness. The internal consistency of the DT's problem list overall and sub-categories were within acceptable range (i.e. $\alpha>0.50$ ). The Receiver Operating Characteristic (ROC) curves and Area Under the Curves (AUC) analysis were significant and found the DT and Problem List to respectively differentiate between cases of distress, anxiety and depression. The DT's cut-off was $>5.0$ with AUC range $(0.754$ $-0.709)$; sensitivity range $(81.0 \%-70.4 \%)$; specificity range $(68.3 \%-65.2 \%)$ for distress, anxiety and depression as determined by HADS. And the Problem List cut-off was $>6.0$ with AUC range $(0.854-0.821)$; sensitivity range $(90.5 \%$ - $85.7 \%)$; specificity range $(68.3 \%-65.2 \%)$ for distress, anxiety and depression as measured by HADS.

Conclusion: The DT and Problem List were found to be valid measures of distress in ART-naïve HIV infected patients.

Keywords: Distress thermometer, validity, psychological distress, ART-naïve, Northern Nigeria.

DOI: https://dx.doi.org/10.4314/ahs.v19i4.40

Cite as: Obiajulu VO, Abiola T, Izehinosen CO, Obiako RO, Aveka IA, Adam BY, Lateef TS. Psychometric validity of the distress thermometer and problem check list in ART-naïe HIV infected patients in Northern Nigeria. Afri Health Sci.2019;19(4):3172-3180. bttps:/ / dx.doi.org/10.4314/abs.v19i4.40
\end{abstract}

\section{Introduction}

Sub-Saharan Africa has the largest burden of HIV/AIDS in the world with Nigeria being the second most affected country within this region. ${ }^{1}$ The trends of HIV/AIDS in

\section{Corresponding author: \\ Victor Olisah Obiajulu, \\ Department of Psychiatry, \\ Ahmadu Bello \\ University, Zaria, Nigeria. \\ Tel. +2348037018902 \\ Email: olisahvictor@yahoo.com}

Nigeria since the first diagnosable case in 1991 reached the highest peak of 5.8\% in 2001 and declined gradually to the current level of $3.1 \%$ in $2016 .{ }^{2}$ The rate of $3.1 \%$ still suggested that large number of Nigerians are affected due to the large population of Nigeria. Despite the large number of People Living with HIV/AIDS (PLWHA) in Nigeria, there is scarcity of studies on their mental health burden. This is because mental illness can occur as direct effect of HIV infection of the brain. ${ }^{3}$ In this respect, a study found a rate of $30 \%$ of psychiatric distress among PLWHA in a clinic in Nigeria. ${ }^{4}$ Another study reported higher rate of mental disorders among Nigerians with HIV/AIDS compared to those without the infection. ${ }^{5}$

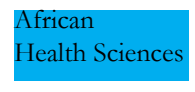

(C) 2019 Obiajulu et al. Licensee African Health Sciences. This is an Open Access article distributed under the terms of the Creative commons Attribution License (https://creativecommons.org/licenses/BY/4.0), which permits unrestricted use, distribution, and reproduction in any medium, provided the original work is properly cited. 
These constituted cases whose mental health burden were unrecognized and hence unmet. Such un-identification can jeopardize the holistic care of PLWHA.

Commonly used instruments to accessed mental health burden of PLWHA include the 12-item General Health Questionnaire, Hospital Anxiety Depression Scale (including its two subscales), the 90-item Symptoms Checklist, Profile of Mood States, Centre for Epidemiological Studies Depression Scale, Beck Depression Inventory, Mongomery-Asberg Depression Rating Scale, Beck Anxiety Inventory, Beck Hopelessness Scale and the Distress Thermometer. ${ }^{4,6-9}$ Among these measuring scales the Distress Thermometer (DT) is the shortest and least demanding measure of psychological distress. Also, searches by the authors showed that it has not been used before among PLWHA in Nigeria. Hence, this study investigated the validity of using the DT and its problem checklist among anti-retroviral therapy naive (ART-naïve) HIV-infected patient in two major hospitals in Kaduna State, North-western Zone of Nigeria.

\section{Methods}

\section{Study population}

Participants were 90 ART-naive and newly diagnosed HIV-infected patients who were not eligible for ART medication on basis of their CD4 count of 400 and above. They were recruited from HIV-clinics of two major hospitals in a State in Northern Nigeria. Ethical approval was obtained from both health institutions Health Research Boards and written informed consent was obtained from each participants before participating in the study.

Instruments of Study

\section{Distress Thermometer and Its Problem Checklist}

The level of psychological distress experienced by the participants was accessed by the Distress Thermometer (DT). The DT is a one-item visual analogue scale that rates the level of distress experienced over the past week on an 11-point ranging from 0 (no distress) to 10 (extreme distress). ${ }^{9}$ The DT also has a Problem List (PL) that helps in identifying the part of life that may be contributing to the distress. The PL problem areas can be grouped into 5 broad categories of practical, family, emotional, spiritual/religious and physical. ${ }^{10}$ The DT and its PL were developed by National Comprehensive Cancer Network for the detection of distress in cancer patients. ${ }^{6}$ However, since cancer is a chronic illness, the DT has been employed in the detection of distress in infectious chronic illnesses like HIV too., ${ }^{9,11}$

\section{Hospital Anxiety Depression Scale (HADS)}

The Hospital anxiety and depression scale (HADS) is an easy to administer measure that screens for the presence of anxiety or depressive state of both clinical and non-clinical population. It consists of seven depression items and seven anxiety items and has been validated for use in Nigeria. ${ }^{12}$ A score of 8 and above on either of the two components is regarded as case. For the purpose of this study, the depression subscale was used.

\section{Oslo social support scale (OSS)}

The OSS-3 provides a brief measure of social functioning and it is considered to be one of the best predictors of mental health.13 It covers different fields of social support by measuring the number of people the respondent feels close to, the interest and concern shown by others, and the ease of obtaining practical help from others. ${ }^{13}$ Its structure and reliability (Crohnbach's alpha of 0.60$)^{13}$ have not been well-documented despite widespread use in several European countries. It has been used and validated in Nigeria. ${ }^{14}$

\section{The 14-item Resilience Scale (RS-14)}

The 14-item Resilience Scale (RS-14) is a measure of psychological resilience, that is, the capacity to withstand life stressors, thrive and make meaning from challenges. This short version is an offshoot of the original 25-item psychological resilience scale of Wagnild and Young's.15 The RS consists of a 17-item "Personal Competence" subscale and an 8-item "Acceptance of Self and Life" subscale for a total of 25 items.16 Resilience as construed by Wagnild comprises of 5 core characteristics of meaning life (purpose), perseverance, self-reliance, equanimity and existential aloneness (i.e. coming home to yourself).17 The RS-14 has also been used and validated in Nigeria.18

\section{Data analysis}

The results were analysed using IBM-SPSS version 21 statistical package. The Pearson Moment Correlation Coefficient was used to assess the relationship of DT with all the measures of psychopathology and wellbeing used in the study. The Cronbach's alpha coefficients were used to determine the internal reliability of DT's Problem List. Cut-off points for DT and its problem list were determined through Receiver Operating Characteristic (ROC) analysis. All statistical evaluations were considered significant at $\mathrm{p}<0.05$, two-tailed. 


\section{Results}

As shown in table 1, majority of the participants were less than 41 years in age $(62.2 \%)$, belonged to the female gender (76.7\%), were of the Christian faith (81.1\%), had at least 12 years of formal education $(88.9 \%)$, currently unmarried (53.3\%) as at the time of assessment and gainfully employed $(75.6 \%)$.

Table 1: Socio-demograhic characteristics of Participants

\begin{tabular}{ll}
\hline Characteristics & At baseline $\mathrm{n}=90(100.0 \%)$ \\
\hline Age group (years) & $56(62.2)$ \\
$\leq 40$ & $34(37.8)$ \\
$41-60$ & $69(76.7)$ \\
Gender & $21(23.3)$ \\
$\quad$ Females & \\
Males & $73(81.1)$ \\
Religion & $17(18.9)$ \\
Christianity & \\
Islam & $42(46.7)$ \\
Marital status & $58(53.3)$ \\
$\quad$ Married & \\
Currently unmarried & $10(11.1)$ \\
Education & $46(51.1)$ \\
Primary & $34(37.8)$ \\
Secondary & \\
Tertiary & $32(35.6)$ \\
Occupation & $21(23.3)$ \\
Self-employed & $15(16.7)$ \\
Government worker & \\
Private $\quad$ business & \\
Worker & $22(24.4)$ \\
Not employed & \\
\hline
\end{tabular}

Table 2 reported that the DT is positively correlated with all the measures of distress and negatively correlated with all the positive wellness measures in this study. The correlations are only significant for the negative measures of psychological wellness.
Table 3 showed that the DT is positively correlated with the total problem list and each of the problem list subscales. The relationship was moderately significant for the emotional problem subscale and overall problem list. The internal consistency of the DT's problem list overall and sub-categories were within acceptable range (i.e. $\alpha>0.50$ ) except for the spiritual/religion unit having only one variable for its determination. 
Table 2: Correlation of Distress Thermometer with other measures (Hospital Anxiety Depression Scale, Oslo Social Support and 14-item Resilience Scale)

\begin{tabular}{|c|c|c|c|c|c|c|c|c|}
\hline Variables & 1 & 2 & 3 & 4 & 5 & 6 & Mean & SD \\
\hline 1. DT & 1 & $0.298^{* *}$ & $0.450^{* *}$ & $0.396^{* *}$ & $\begin{array}{l}- \\
0.052\end{array}$ & $\begin{array}{l}- \\
0.137\end{array}$ & 4.86 & 3.501 \\
\hline $\begin{array}{l}\text { 2. HADS } \\
\text { Depression }\end{array}$ & & 1 & $0.798^{* *}$ & $0.946^{* *}$ & $\begin{array}{l}- \\
0.131\end{array}$ & $\begin{array}{l}- \\
0.230^{*}\end{array}$ & 4.66 & 4.909 \\
\hline $\begin{array}{l}\text { 3. HADS } \\
\text { Anxiety }\end{array}$ & & & 1 & $0.951^{* *}$ & $\begin{array}{l}- \\
0.185\end{array}$ & $\begin{array}{l}- \\
0.171\end{array}$ & 5.40 & 5.129 \\
\hline $\begin{array}{l}\text { 4. HADS } \\
\text { Overall }\end{array}$ & & & & 1 & $\begin{array}{l}- \\
0.167\end{array}$ & $\begin{array}{l}- \\
0.211^{*}\end{array}$ & 10.06 & 9.51800 \\
\hline 5. OSS & & & & & 1 & $0.237^{*}$ & 10.74 & 2.296 \\
\hline 6. RS & & & & & & 1 & 79.01 & 14.644 \\
\hline
\end{tabular}

Table 3: Correlation of Distress Thermometer with its Problem Check List and its subscales

\begin{tabular}{|c|c|c|c|c|c|c|c|c|}
\hline & 1 & 2 & 3 & 4 & 5 & 6 & 7 & Crobach's alpha \\
\hline 1. DT & 1 & 0.191 & 0.184 & $0.427^{* *}$ & 0.110 & .185 & $0.355^{* *}$ & - \\
\hline $\begin{array}{l}\text { 2.Practical } \\
\text { problem }\end{array}$ & & 1 & $0.388^{* *}$ & $0.304^{* *}$ & $0.325^{* *}$ & $.0382^{* *}$ & $0.652^{* *}$ & 0.748 \\
\hline $\begin{array}{l}\text { 3.Family } \\
\text { problem }\end{array}$ & & & 1 & $0.454^{* *}$ & $0.399^{* *}$ & 0.092 & $0.532^{* *}$ & 0.647 \\
\hline $\begin{array}{l}\text { 4.Emotional } \\
\text { problem }\end{array}$ & & & & 1 & $0.339^{* *}$ & $0.242^{*}$ & $0.699^{* *}$ & 0.896 \\
\hline $\begin{array}{l}\text { 5.Spiritual } \\
\text { problem }\end{array}$ & & & & & 1 & $0.397^{* *}$ & $0.560^{* *}$ & - \\
\hline $\begin{array}{l}\text { 6.Physical } \\
\text { problem }\end{array}$ & & & & & & 1 & $0.789^{* *}$ & 0.856 \\
\hline $\begin{array}{l}\text { 7.Problem list } \\
\text { total }\end{array}$ & & & & & & & 1 & 0.881 \\
\hline
\end{tabular}

As displayed in figures 1-6, the Receiver Operating Characteristic (ROC) curves and Area under the Curves (AUC) analysis were significant and found the DT and Problem List to respectively differentiate between cases of distress, anxiety and depression. At the DT's cut-off of $\geq 5.5$; the AUC range was from 0.754 to 0.709 ); with sensitivity range of $81.0 \%-70.4 \%$; and specificity range of $68.3 \%-65.2 \%$; for anxiety, depression and total distress as determined by HADS. At this cut-off point of $\geq 5.5$, the DT screened $73.3 \%$ of the participants as having psychological distress. Lastly, at the Problem List cutoff of $\geq 6.5$ the AUC ranged from 0.854 to 0.821 ; with sensitivity range of $90.5 \%-85.7 \%$; and specificity range of $68.3 \%-65.2 \%$; for anxiety, depression and total distress as measured by HADS. 
Figure 1: The ROC curve for distress thermometer and depression subscale of hospital anxiety depression scale. also displayed is the AUC and other parameters

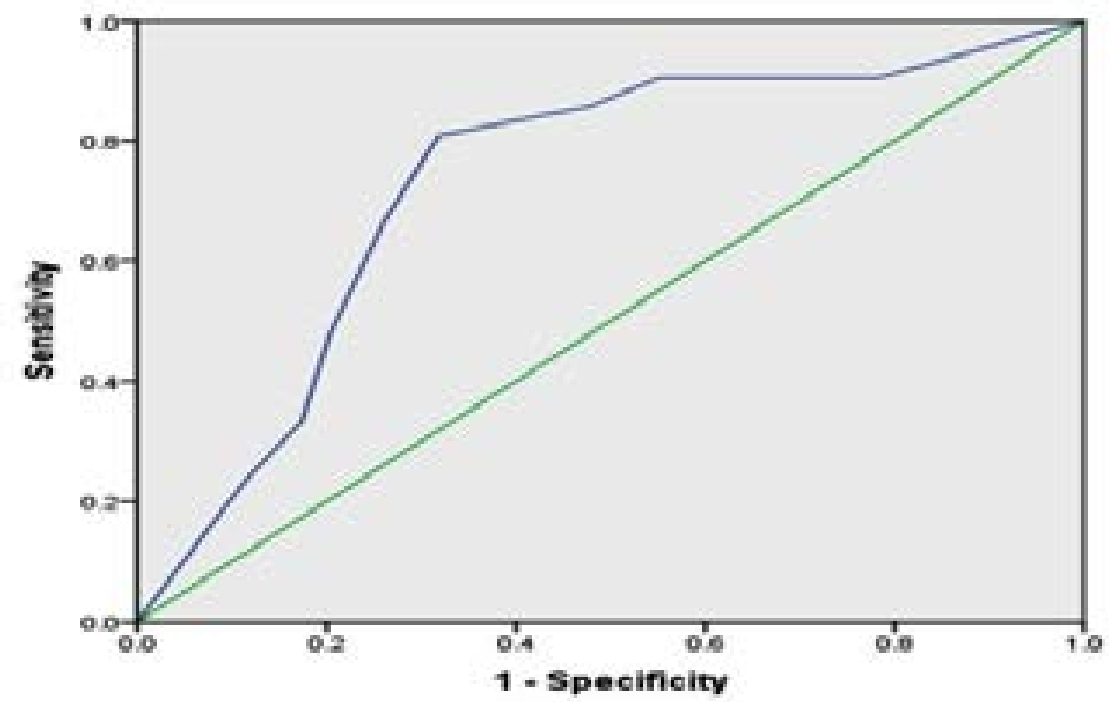

Legends: AUC 0.732, z 0.062, p-value 0.001 Cut-off $\geq 5.5$, Sensitivity $81.0 \%$, Specificity $68.1 \%$

Figure 2: The ROC curve for distress thermometer and anxiety subscale of hospital anxiety depression scale. also displayed is the AUC and other parameters.



Legends: AUC 0.754, z 0.053, p-value 0.001, Cut-off $\geq 5.5$, Sensitivity $71.4 \%$, Specificity $65.2 \%$ 
Figure 3: The ROC curve for distress thermometer and hospital anxiety depression scale total score. also displayed is the AUC and other parameters

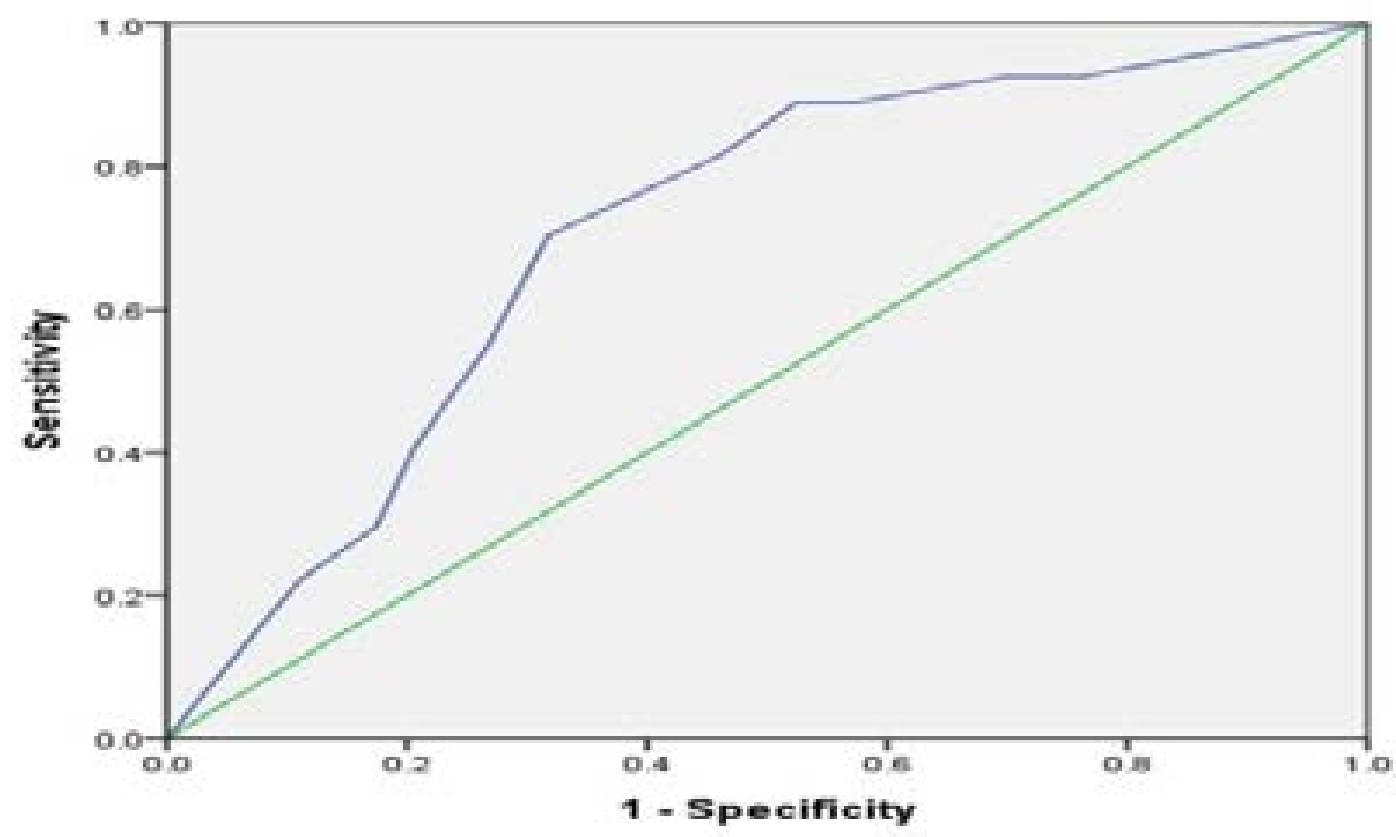

Legends: AUC 0.709, z 0.058, p-value 0.002, Cut-off $\geq 5.5$, Sensitivity $70.4 \%$, Specificity $68.3 \%$

Figure 4: The ROC curve for distress thermometer problem list and depression subscale of hospital anxiety depression scale. Also displayed is the AUC and other parameters

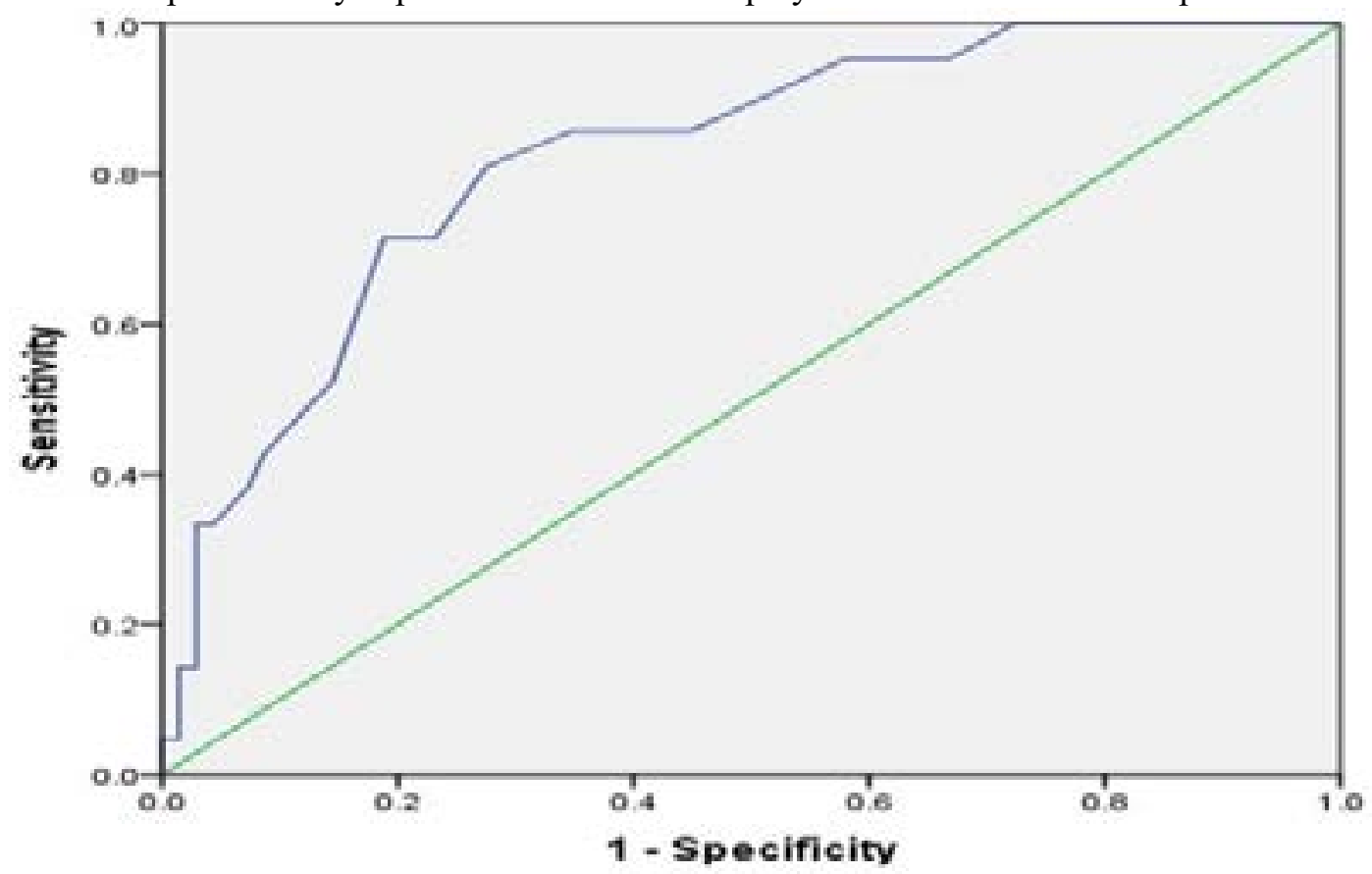

Legends: AUC $0.823, z$ 0.049, p-value $<0.001$, Cut-off $\geq 6.5$, Sensitivity $85.7 \%$, Specificity $65.2 \%$ 
Figure 5: The ROC curve for distress thermometer problem list and anxiety subscale of hospital anxiety depression scale. Also displayed is the AUC and other parameters

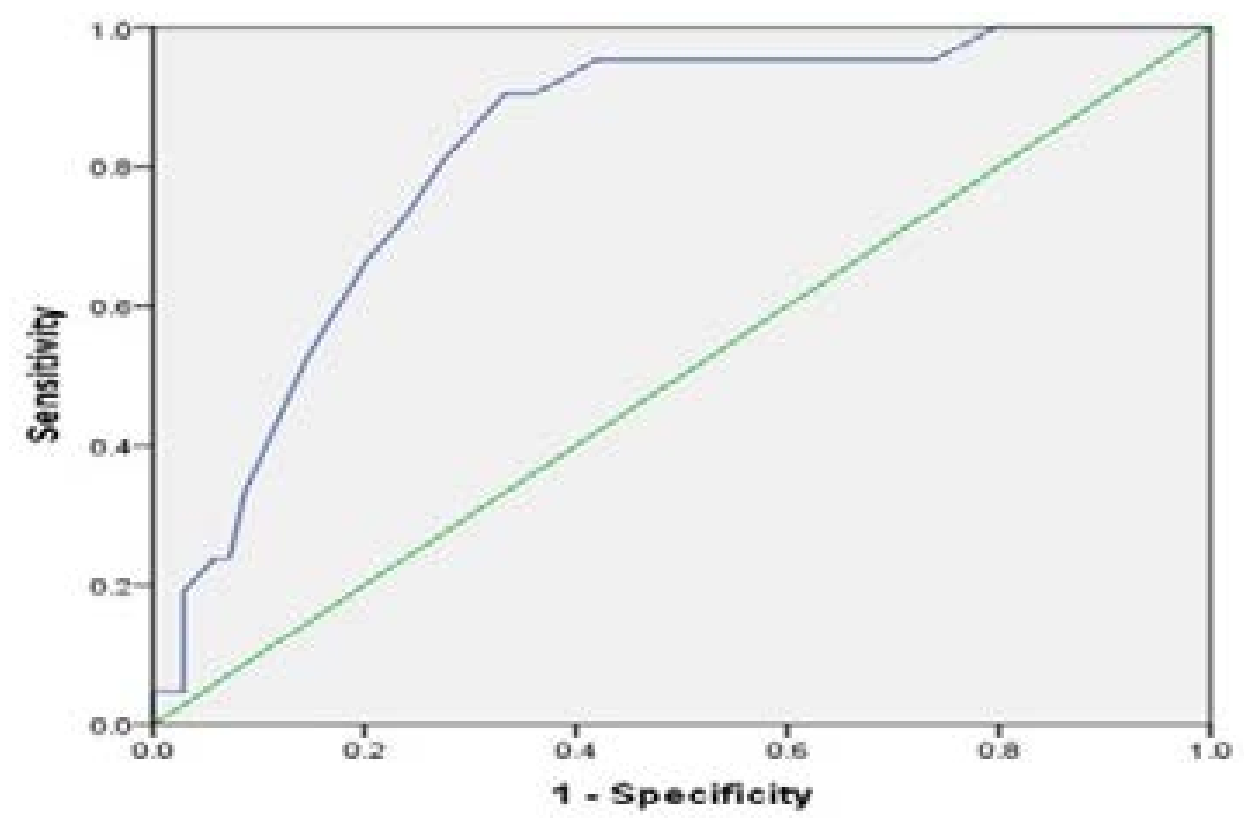

Legends: AUC 0.821,z 0.048,p-value $<0.001$, Cut-off $\geq 6.5$, Sensitivity 90.5\%, Specificity 66.7\%

Figure 6: The ROC curve for distress thermometer problem list and hospital anxiety depression scale total score. Also displayed is the AUC and other parameters

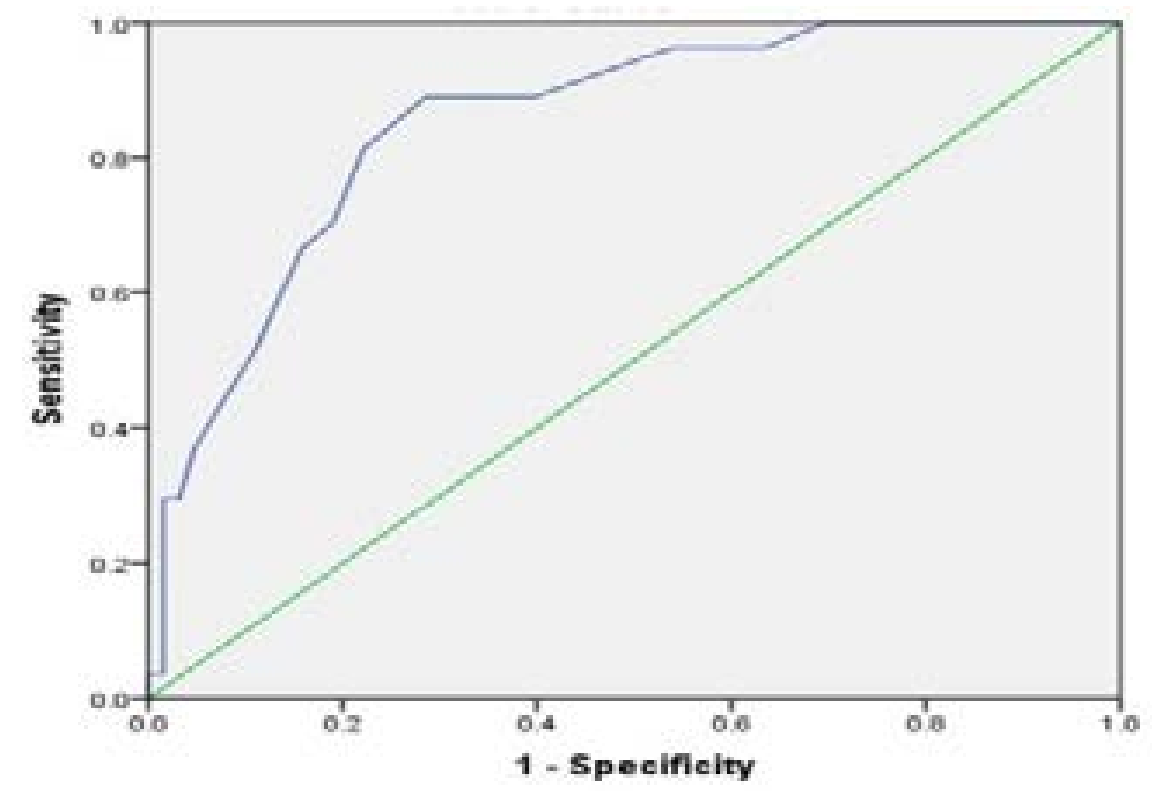

Legends: AUC 0.854, z 0.041 , p-value $<0.001$, Cut-off $\geq 6.5$, Sensitivity $88.9 \%$,Specificity $68.3 \%$ 


\section{Discussion}

The primary purpose of this study was to assess the psychometric validity of the DT and its Problem List in ART-naive HIV-infected patients. The study found DT to be positively correlated with all measure of psychopathology and negatively with wellbeing measures. These findings were similar to previous studies results ${ }^{9,10}$ in terms of concurrent validity of DT with other measures of psychopathology used in this study. The reverse correlation of DT with measures of wellbeing in this study do suggested that distress is more than just the presence of anxiety, depressive or other unpleasant emotional experiences ${ }^{8}$ but also the absence of wellbeing attributes. However, that the relationship of DT with social support and resilience were not significant made this observation at now speculative.

The AUCs of the DT with HADS total and subscales' scores were above 0.5 which were significant and gave a cut-off point of $\geq 5.5$ with sensitivity and specificity always above $65 \%$. This met the criteria for a mood scale. ${ }^{19}$ The Cronbach's alphas of the DT PCL and its subscales fall within the acceptable range and hence internally reliable. This suggested each of the subscales can be used individually in addition to its total problem list in starting a conversion about patient's subjective feeling of distress and how to help them manage them using evidence-based standards. ${ }^{20}$

Based on the DT's cut-off point of $\geq 5.5,73.3 \%$ of the participants had psychological distress. This rate was similar to a previous study ${ }^{9}$ prevalence $(72.3 \%)$ from a developed country suggesting the utility of DT cross-culturally. Also, DT screened out more patients with distress compared with a previous study in Nigeria ${ }^{4}$ using GHQ12 suggesting that DT is not only short, less cumbersome but also appeared to be a better tool in identifying psychological distress among HIV-infected patients.

Patients that had distress were more likely to have relatively moderate and significant emotional problems and overall problem lists. This pattern differs from previous studies using DT that often found most of the subscales being significantly related. However, this might be due to some of those studies being carried out among cancer patients. ${ }^{10,21}$ Also, that the spiritual dimension was not significantly associated with DT was surprising considering that most Nigerian engaged often in religious practices. Hence, we advocated that future study should ex- plore further the role of religion/spirituality with distress among HIV-infected participants.

\section{Limitations}

The sample had a skewed gender representative (i.e. $76.7 \%$ were females). Hence, deduction from this study will more likely be generalizable to the female gender than otherwise. The use of HADS as a 'gold standard' tool to clarify the presence or absence of psychological distress during the ROC analysis has been a challenge on the ground that HADS is not a diagnostic instrument. However, DT measure is more than the presence of anxiety and depression but of unpleasant emotional distress that the HADS total scale's score is measuring. Despite these limitations, the present study included other measure of mental health beyond psychopathology by including positive measures of wellbeing.

\section{Conclusion}

The DT and Problem List were found from this study to be valid measures of distress in ART-naïve HIV infected patients. This study hence advocates to the attending physicians to utilize the DT as a very brief and less cumbersome screening tool to assess patients' psychological distress level and to intervene as appropriate by referring to a mental health expert for further assessment and treatments. Such further interventions must be guided by evidence-based standards.

\section{Acknowledgements}

We are grateful to the doctors and nurses at the Ahmadu Bello University Teaching Hospital

Zaria HIV/AIDs Treatment and Care Centre and the Saint Geralds Catholic Hospital HIV treatment unit (Caritas Catholic Relief Foundation HIV Centre) for their help during data

collection.

\section{Conflict of interest}

None declared.

\section{References}

1.bJoint United Nations Programme on HIV and AIDS, 2015. Factsheet 2015: Word AIDS Day 2015.

2. Awofala, A.A. and Ogundele, O.E. HIV epidemiology in Nigeria. Saudi J Biol Sci, 2016. http://dx.doi. org/10.1016/j.sjbs.2016.03.006 
3. World Health Organization. HIV/AIDS and mental health - report by secretariat. Geneva, World Health Organization, 2008. http://apps.who.int/gb/archive/pdf_ files/EB124/B124_6-en.pdf

4. Olagunju, A. T.,Adeyemi, J. D., Erinfolami, A. R., Aina, O. F. HIV/AIDS and psychological distress: The experience of outpatients in a West African HIV clinic. HIV \& AIDS Rev, 2012; 11:31-35.

5. Adewuya, A., Afolabi M. O., Ola, B. A., Ogundele, O., Ajibare, A. O., Oladipo, B. F. Psychiatric disorders among HIV-positive population in Nigeria: a control study. Journal of Psychosomatic Research, 2007; 63(2)203-206.

6. Griffin, K. W. and Rabkin, J. G. Psychological distress in people with HIV/AIDS: prevalence rates and methodological issues. AIDS Behav, 1997; 1(1):29-42.

7. Solomon, H. T. and Girma, T. B. Generalized psychological distress among HIV-infected patients enrolled in antiretroviral treatment in Dilla University Hospital, Gedeo Zone, Ethiopia. Global Health Action, 2014.

8. Blashill, A. J., Gordon, J. R., Safren, S. A. Appearance concerns and psychological distress among HIV-infected individuals with injecting drug use histories: Prospective analyses. AIDS Patient Care STDs, 2012; 26(9):557-561.

9. Cohen, M. A., Hoffman, R. G., Cromwell, C., Schmeidler, J., Ebrahim, F., Carrera, G.et al.. The prevalence of distress in persons with human immunodeficiency virus infection. Psychosomatics, 2002; 43:10-15 PubMed. 10. Schofield, P. E. , Butow, P. N., Thompson, J. F., Tattersall, M. H. N., Beeney, L. J., Dunn, S. M. Psychological responses of patients receiving a diagnosis of cancer. Ann Oncol, 2003; 14(1): 48-56.

11. National Comprehensive Cancer Network (2010) Clinical practice guidelines in oncology-v.1.2010. Distress management. version1.

12. Abiodun, O. A. A validity study of the Hospital Anx- iety and Depression Scale in general hospital units and a community sample in Nigeria. The Br J Psychiatry, 1994; 165: 669-672 PubMed .

13. Dalgard, O. S., Bjork, S., Tambs, K. Social support, negative life events and mental health. Br J Psychiatry, 1995; 166:29-34 PubMed.

14. Abiola, T., Udofia, O. , Zakari, M. Psychometric Properties of the 3-Item Oslo Social Support Scale among Clinical Students of Bayero University Kano, Nigeria. Malays J Psychiatry, 2013; 22 (2):1-10

15. Wagnild, G. M. and Young, H. M. (1993): The Resilience Scale and 14-Item Resilience Scale; on; https:/ / www.resiliencescale.com/permission. html browsed on 04/06/10.

16. Wagnild, G. M. and Young, H. M. Development and psychometric evaluation of the Resilience Scale. J Nurs Meas.1993; 1(2): 165-78.

17. Wagnild, G. M. (2010): Discovering Your Resilience Core, on https://www.resiliencescale.com/permission. html browsed on 07/09/10

18. Abiola, T. and Udofia, O. Psychometric assessment of the Wagnild and Young's resilience scale in Kano, Nigeria. BMC Res Notes, 2011; 4: 1-5 PubMed.

19. Bennett, H, E. and Lincoln, N.B. (2006). Potential screening measures for depression and anxiety after stroke. Int J Ther Rehabil,13(9): 401-406.

20. British Psychological Society. British HIV Association \& Medical Foundation for AIDS \& Sexual Health. Standards for psychological support for adults living with HIV. Medical Foundation for AIDS \& Sexual Health (MedFASH), 2011, BMA House, Tavistock, London, WC1H9JP.

21. Hong, J. S. and Tian, J. Sensitivity and specificity of the Distress Thermometer in screening for distress in long-term nasopharyngeal cancer survivors. Curr Oncol, 2013; 20(6): 570-576 